\title{
Association between PSCA gene polymorphisms and the risk of cancer: an updated meta-analysis and trial sequential analysis
}

\author{
Zhiqiang Qin ${ }^{1, *}$, Jingyuan Tang ${ }^{2,}{ }^{*}$, Xiao $\mathrm{Li}^{3,}{ }^{*}$, Yajie $\mathrm{Yu}^{1}$, Chuanjie Zhang ${ }^{4}$, Peng Han ${ }^{1}$, \\ Ran Li ${ }^{1}$, Xuping Jiang ${ }^{5}$, Chengdi Yang ${ }^{1}$, Wei Wang ${ }^{1}$, Min Tang ${ }^{1}$ and Wei Zhang ${ }^{1}$ \\ ${ }^{1}$ Department of Urology, The First Affiliated Hospital of Nanjing Medical University, Nanjing, 210029, China \\ ${ }^{2}$ Department of Urology, Wuxi Second People's Hospital, Nanjing Medical University, Wuxi, 214002, China \\ ${ }^{3}$ Department of Urologic Surgery, The Affiliated Cancer Hospital of Jiangsu Province of Nanjing Medical University, Nanjing, \\ 210009, China \\ ${ }^{4}$ First Clinical Medical College of Nanjing Medical University, Nanjing, 210029, China \\ ${ }^{5}$ Department of Urology, Yixing People's Hospital, Wuxi, 214200, China \\ *These authors are contributed equally to this work
}

Correspondence to: Wei Zhang, email: zhangwei_urology@sina.com

Min Tang, email: mintang@njmu.edu.cn

Keywords: PSCA polymorphisms, rs2294008, rs2976392, cancer, meta-analysis

Received: October 21, 2016 Accepted: March 30, $2017 \quad$ Published: April 10, 2017

Copyright: Qin et al. This is an open-access article distributed under the terms of the Creative Commons Attribution License 3.0 (CC BY 3.0), which permits unrestricted use, distribution, and reproduction in any medium, provided the original author and source are credited.

\section{ABSTRACT}

Previous studies have investigated the relationships between PSCA rs2294008 C>T and rs2976392 G >A polymorphisms and cancer susceptibility. However, the available findings remained inconsistent and even controversial. Thus, the aim of this meta-analysis was performed to clarify such associations. The online databases PubMed, EMBASE and Web of Science searched for relevant studies, covering all the papers published until September 1st, 2016. Data were pooled by odds ratios (ORs) with $95 \%$ confidence intervals (CIs) to evaluate the strength of such associations. Then, trial sequential analysis was performed to estimate whether the evidence of the results was firm. Overall, a significant increased risk of cancer was associated with PSCA rs2294008 C >T and rs2976392 G >A polymorphisms. For the PSCA rs2294008 polymorphism, when stratified by type of cancer, the results were significant especially in gastric cancer and bladder cancer. Moreover, in the subgroup analysis by ethnicity, significant results were detected in both Asian and Caucasian populations. Similarly, for the PSCA rs2976392 polymorphism, the stratification analyses by type of cancer showed that the results were significant only in gastric cancer. In addition, the stratification analyses by ethnicity detected that this polymorphism increased cancer risk only in Asian populations. Then, trial sequential analyses demonstrated that the results of the meta-analysis were based on sufficient evidence. Therefore, this meta-analysis suggested that the PSCA rs2294008 C>T and rs2976392 G>A polymorphisms might be associated with cancer susceptibility, which might act as a potential predicted biomarker for genetic susceptibility to cancer, especially in gastric cancer and bladd er cancer.

\section{INTRODUCTION}

Despite the obvious improvements in the early diagnosis and treatment of cancer, cancer remains amajor worldwide public health burden in recent year, with approximately 1,688,780 new cases and 600,920 new deaths in the United States in 2017 [1]. Cancer is a multistep complex and multifactorial disease involving the intricate interactions between numerous genetic as well as environmental risk factors, such as age, race, lifestyle, obesity, family history, smoking status and endocrine system [2-4]. It is well known that various genes are 
associated with the carcinogenesis due to the polygenic inheritanc of cancer [5]. However, the exact mechanism of cancer is unclear and remains to be identified. Multiple studies have shown that the screening and identification of single-nucleotide polymorphisms (SNPs) as a predicted biomarker of human genetic variation might affect individual in the sensitivity to cancer risk and therapeutic responses in early cancer patients. Therefore, it has been demonstrated that SNPs may play an important role in high susceptibility for cancer to discover novel loci or genes [6].

As a LY-6/Thy-1 family of cell surface antigens, prostate stem cell antigen (PSCA) gene is located on chromosome 8q24.2 containing 464 SNPs, and the PSCA protein is a 123-amino-acid cell membrane glycoprotein, which encodes a PSCA protein that is reported as a cell surface marker [7]. Compared to the normal tissues, PSCA is further up-regulated in prostate cancer tissue, and which is also found in several other cancers, including pancreatic cancer and gallbladder cancer [8-10]. Moreover, as the most extensively studied SNPs in the PSCA gene, rs2294008 $\mathrm{C}>\mathrm{T}$ and $\mathrm{rs} 2976392 \mathrm{G}>\mathrm{A}$ are shown to be associated with increased risk of bladder and stomach cancers $[11,12]$. However, there is no obvious evidence for the role of PSCA in carcinogenesis. Thus, it was hypothesized that PSCA gene polymorphisms were likely to play an vital role in carcinogenesis.

In recent years, several studies have been widely investigated the possible association between the PSCA polymorphisms and risk of cancer. For instance, Qiu et al. [13] demonstrated that the PSCA rs2294008 T alleles was risk factors for gastric cancer in this eastern Chinese population. However, Mou et al. [19] found that PSCA rs2294008 polymorphism possessed no difference/ association with gastric cancer risk among cases and controls. Hence, we cannot definitively declare that the observed association between PSCA polymorphisms and risk of cancer. So, we aimed to conduct a meta-analysis including all accessible case-control studies to reconcile all the discordant results to systematically clarify the role of these SNPs in susceptibility to cancer. Additionally, lack of further research in trial sequential analysis (TSA) prevented comprehensive understanding of the association between PSCA polymorphisms and cancer susceptibility in some previous meta-analyses. Hence, with this in mind, we conducted the present meta-analysis and TSA to critically evaluate the association between PSCA rs2294008 C $>$ T and rs2976392 G>A polymorphisms and cancer risk and clarify whether the evidence for the results was sufficient.

\section{RESULTS}

\section{Studies characteristics}

A total of 41 case-control studies were found to fulfill the eligibility criteria for the current meta-analysis of the PSCA rs2294008 and rs2976392 with cancer risk including 34,764 patients and 43,309 controls [11-48], and the detailed characteristics of individual studies included were listed in Table 1. Besides, the distribution of genotypes in the controls was consistent between HardyWeinberg equilibrium (HWE) in all involved studies except two articles [13, 37]. Figure 1 showed the flowchart of literature search and selection process.

For the PSCA rs2294008 polymorphism, 38 studies were performed on investigating the association between this SNP with susceptibility of cancer, including 34,266 cases and 42,764 controls [11-45]. In these studies, there were 26 studies of Asian populations and the other 12 studies were Caucasian ethnicity. The studied type of cancer included gastric cancer, breast cancer, cervical cancer, colorectal cancer, bladder cancer, esophageal cancer, gallbladder cancer and prostate cancer. Besides, seven genotyping methods were applied, such as Taqman, Sequenom, PCR-RFLP, DHPLC, HRM, GWAS and PCR/ LDR. Furthermore, we divided them into population-based group or hospital-based group in all studies to distinguish between different sources of control group. Similarly, for the PSCA rs2976392 polymorphism, there were 18 studies exploring the relationship between this polymorphism and risk of overall cancer with 10,501 cases and 9,766 controls [12-14, 18, 20-21, 23, 28, 32, 36, 40-41, 43-44, 46-48]. In regard to source of control, the studies consisted of 3 population-based controls and 15 hospital-based controls. Moreover, there were 16 Asian populations and 2 Caucasian populations. In addition, the studied cancer type included gastric cancer, prostate cancer, colorectal cancer, breast cancer, and gallbladder cancer.

\section{Quantitative synthesis results}

The main results of this meta-analysis of the associations between PSCA rs2294008 C $>$ T and rs2976392 G>A polymorphisms and risk of cancer were showed in Supplementary Table 1. Overall, our results indicated that PSCA rs2294008 C > T polymorphism was associated with an increased risk of cancer (dominant model: pooled $\mathrm{OR}=1.28,95 \% \mathrm{CI}$ : $1.17-1.41$; recessive model: pooled $\mathrm{OR}=1.10,95 \% \mathrm{CI}$ : 0.99-1.22; homozygote model: pooled OR=1.30 95\% CI: 1.14-1.48; heterozygote model: pooled $\mathrm{OR}=1.27,95 \% \mathrm{CI}$ : 1.14-1.48; allele model: pooled $\mathrm{OR}=1.15,95 \% \mathrm{CI}: 1.08-1.22$ ) in the random-effects model. When stratified by type of cancer, the results showed PSCA rs2294008 had significantly increased risk of gastric cancer (dominant model: pooled $\mathrm{OR}=1.45$, 95\% CI: 1.27-1.66; recessive model: pooled $\mathrm{OR}=1.14,95 \% \mathrm{CI}:$ 0.95-1.36; homozygote model: pooled $\mathrm{OR}=1.46$ 95\% CI: 1.17-1.83; heterozygote model: pooled $\mathrm{OR}=1.43$, 95\% CI: 1.27-1.60; allele model: pooled OR $=1.22,95 \%$ CI: 1.10-1.35) and bladder cancer (dominant model: pooled $\mathrm{OR}=1.26,95 \% \mathrm{CI}: 1.19-1.32$; recessive model: pooled OR $=1.18,95 \% \mathrm{CI}$ : 1.07-1.19; homozygote 
Table 1: Characteristics of individual studies included in the meta-analysis

\begin{tabular}{|c|c|c|c|c|c|c|c|c|c|c|c|c|c|c|c|c|}
\hline \multirow{2}{*}{$\begin{array}{c}\text { PSCA } \\
\text { Year }\end{array}$} & \multirow{2}{*}{$\begin{array}{c}\text { rs2294008 } \\
\text { Author }\end{array}$} & \multirow[b]{2}{*}{ Country } & \multirow[b]{2}{*}{ Ethnicity } & \multirow[b]{2}{*}{ SOC } & \multirow[b]{2}{*}{ Genotyping } & \multirow[b]{2}{*}{$\begin{array}{l}\text { Type of } \\
\text { Cancer }\end{array}$} & \multirow[b]{2}{*}{ Case } & \multirow[b]{2}{*}{ Control } & \multicolumn{3}{|c|}{ Case(n) } & \multicolumn{3}{|c|}{ Control(n) } & \multirow[b]{2}{*}{$\begin{array}{l}\text { NOS } \\
\text { points }\end{array}$} & \multirow[b]{2}{*}{ HWE } \\
\hline & & & & & & & & & $\mathrm{CC}$ & CT & TT & $\mathrm{CC}$ & $\mathrm{CT}$ & TT & & \\
\hline 2016 & Qiu & China & Asian & $\mathrm{HB}$ & Taqman & Gastric & 1124 & 1192 & 537 & 489 & 98 & 663 & 383 & 146 & 8 & $\mathrm{~N}$ \\
\hline 2016 & Wang & China & Asian & $\mathrm{HB}$ & Sequenom & Breast & 560 & 583 & 273 & 231 & 56 & 299 & 247 & 37 & 8 & $\mathrm{Y}$ \\
\hline 2016 & Wang & China & Asian & $\mathrm{HB}$ & Taqman & Cervical & 1126 & 1237 & 609 & 469 & 48 & 618 & 527 & 92 & 9 & $\mathrm{Y}$ \\
\hline 2015 & $\begin{array}{c}\text { Garcia- } \\
\text { Gonzalez }\end{array}$ & Spain & Caucasian & $\mathrm{HB}$ & Taqman & Gastric & 603 & 675 & 154 & 302 & 147 & 199 & 346 & 130 & 9 & $\mathrm{Y}$ \\
\hline 2015 & Ichikawa & Japan & Asian & $\mathrm{HB}$ & PCR-RFLP & Gastric & 193 & 266 & 24 & 104 & 65 & 52 & 119 & 95 & 7 & $\mathrm{Y}$ \\
\hline 2015 & Sun & China & Asian & $\mathrm{HB}$ & Taqman & Gastric & 692 & 774 & 322 & 309 & 61 & 405 & 297 & 72 & 9 & $\mathrm{Y}$ \\
\hline 2015 & Kupcinskas & Latvia & Caucasian & $\mathrm{HB}$ & Taqman & Colorectal & 191 & 377 & 60 & 77 & 54 & 100 & 189 & 88 & 7 & $\mathrm{Y}$ \\
\hline 2015 & Zhang & China & Asian & $\mathrm{HB}$ & Sequenom & Gastric & 475 & 480 & 227 & 207 & 41 & 261 & 183 & 36 & 8 & Y \\
\hline 2015 & Mou & China & Asian & PB & DHPLC & Gastric & 198 & 130 & 23 & 126 & 49 & 5 & 34 & 91 & 9 & $\mathrm{Y}$ \\
\hline 2014 & Kupcinskas & Lithuania & Caucasian & $\mathrm{HB}$ & Taqman & Gastric & 251 & 243 & 33 & 116 & 102 & 64 & 123 & 56 & 8 & $\mathrm{Y}$ \\
\hline 2014 & Lee & Korea & Asian & $\mathrm{HB}$ & HRM & Bladder & 411 & 1700 & 70 & 222 & 119 & 414 & 818 & 468 & 9 & Y \\
\hline 2014 & Wang & China & Asian & PB & Taqman & Bladder & 1210 & 1008 & 604 & 509 & 97 & 566 & 376 & 66 & 9 & $\mathrm{Y}$ \\
\hline 2014 & Sun & USA & Caucasian & $\mathrm{HB}$ & Taqman & Gastric & 130 & 125 & 17 & 64 & 49 & 30 & 63 & 32 & 9 & $\mathrm{Y}$ \\
\hline 2014 & Dai & China & Asian & PB & Taqman & Esophageal & 2083 & 2220 & 1232 & 724 & 127 & 1222 & 851 & 147 & 9 & $\mathrm{Y}$ \\
\hline 2013 & Zhao & China & Asian & PB & DHPLC & Gastric & 717 & 951 & 275 & 342 & 100 & 465 & 401 & 85 & 8 & $\mathrm{Y}$ \\
\hline 2013 & Rizzato & Germany & Caucasian & PB & Taqman & Gastric & 178 & 1057 & 23 & 86 & 69 & 231 & 507 & 319 & 9 & $\mathrm{Y}$ \\
\hline 2013 & Rai & India & Asian & HB & Taqman & Gallbladder & 405 & 247 & 104 & 233 & 68 & 79 & 126 & 42 & 7 & $\mathrm{Y}$ \\
\hline 2013 & Ono & Japan & Asian & HB & Taqman & Gallbladder & 44 & 173 & 9 & 23 & 12 & 30 & 75 & 68 & 8 & $\mathrm{Y}$ \\
\hline 2013 & $\mathrm{Ma}$ & China & Asian & PB & MassARRAY & Bladder & 175 & 962 & 84 & 80 & 11 & 543 & 355 & 64 & 9 & $\mathrm{Y}$ \\
\hline 2012 & Smith & Scotland & Caucasian & HB & Taqman & Colorectal & 77 & 804 & 25 & 39 & 13 & 287 & 387 & 130 & 7 & $\mathrm{Y}$ \\
\hline 2012 & Sala & European & Caucasian & PB & Taqman & Gastric & 409 & 1515 & 93 & 198 & 118 & 491 & 714 & 310 & 9 & $\mathrm{Y}$ \\
\hline 2012 & $\mathrm{Li}$ & China & Asian & PB & MassARRAY & Gastric & 300 & 300 & 124 & 141 & 35 & 168 & 111 & 21 & 8 & $\mathrm{Y}$ \\
\hline 2012 & Kim & Korea & Asian & HB & MassARRAY & Breast & 451 & 459 & 119 & 216 & 116 & 113 & 240 & 106 & 8 & $\mathrm{Y}$ \\
\hline 2012 & $\mathrm{Fu}$ & $\begin{array}{c}\text { European } \\
\& U S A\end{array}$ & Caucasian & PB & GWAS & Bladder & 5393 & 7324 & 1363 & 2804 & 1226 & 2107 & 3645 & 1572 & 9 & $\mathrm{Y}$ \\
\hline 2011 & Zeng & China & Asian & HB & PCR-RFLP & Gastric & 460 & 549 & 202 & 216 & 42 & 289 & 223 & 37 & 8 & $\mathrm{Y}$ \\
\hline 2011 & Song & Korea & Asian & HB & PCR-RFLP & Gastric & 3245 & 1700 & 576 & 1620 & 1049 & 414 & 818 & 468 & 9 & $\mathrm{Y}$ \\
\hline 2011 & Lochhead & USA & Caucasian & PB & Taqman & Esophageal & 158 & 208 & 61 & 63 & 34 & 49 & 110 & 49 & 9 & $\mathrm{Y}$ \\
\hline 2011 & Lochhead & USA & Caucasian & PB & Taqman & Gastric & 308 & 208 & 85 & 129 & 94 & 49 & 110 & 49 & 9 & $\mathrm{Y}$ \\
\hline 2011 & Lochhead & Poland & Caucasian & PB & Taqman & Gastric & 292 & 382 & 47 & 143 & 102 & 101 & 166 & 115 & 8 & $\mathrm{~N}$ \\
\hline 2011 & Joung & Korea & Asian & $\mathrm{HB}$ & MassARRAY & Prostate & 192 & 168 & 45 & 98 & 49 & 47 & 84 & 37 & 9 & $\mathrm{Y}$ \\
\hline 2010 & Wang & China & Asian & HB & PCR-RFLP & Bladder & 581 & 580 & 272 & 259 & 50 & 316 & 220 & 44 & 7 & $\mathrm{Y}$ \\
\hline 2010 & $\mathrm{Ou}$ & China & Asian & $\mathrm{HB}$ & PCR/LDR & Gastric & 196 & 246 & 85 & 93 & 18 & 132 & 96 & 18 & 8 & $\mathrm{Y}$ \\
\hline 2010 & $\mathrm{Lu}$ & China & Asian & PB & PCR-RFLP & Gastric & 1023 & 1069 & 547 & 404 & 72 & 605 & 387 & 77 & 8 & $\mathrm{Y}$ \\
\hline 2009 & $\mathrm{Wu}$ & European\&USA & Caucasian & HB & GWAS & Bladder & 5038 & 9363 & 1288 & 2613 & 1137 & 2842 & 4668 & 1853 & 9 & $\mathrm{Y}$ \\
\hline 2009 & $\mathrm{Wu}$ & China & Asian & PB & PCR-RFLP & Gastric & 1710 & 995 & 759 & 819 & 132 & 506 & 412 & 77 & 9 & $\mathrm{Y}$ \\
\hline 2009 & Matsuo & Japan & Asian & $\mathrm{HB}$ & Taqman & Gastric & 708 & 708 & 330 & 329 & 49 & 273 & 338 & 97 & 8 & $\mathrm{Y}$ \\
\hline 2008 & Sakamoto & Korea & Asian & HB & Taqman & Gastric & 871 & 390 & 133 & 461 & 277 & 122 & 176 & 92 & 7 & $\mathrm{Y}$ \\
\hline 2008 & Sakamoto & Japan & Asian & $\mathrm{HB}$ & GWAS & Gastric & 1524 & 1396 & 96 & 700 & 728 & 210 & 650 & 536 & 9 & $\mathrm{Y}$ \\
\hline PSCA & rs2976392 & & & & & & & & & & & & & & & \\
\hline
\end{tabular}




\begin{tabular}{|c|c|c|c|c|c|c|c|c|c|c|c|c|c|c|c|c|}
\hline Year & Surname & Country & Ethnicity & SOC & Genotyping & $\begin{array}{l}\text { Type of } \\
\text { Cancer }\end{array}$ & Case & Control & GG & GA & $\mathrm{AA}$ & GG & GA & $\mathrm{AA}$ & & HWE \\
\hline 2016 & Qiu & China & Asian & HB & Taqman & Gastric & 1124 & 1192 & 535 & 488 & 101 & 682 & 388 & 122 & 8 & $\mathrm{~N}$ \\
\hline 2016 & Wang & China & Asian & HB & Sequenom & Breast & 560 & 583 & 287 & 230 & 43 & 298 & 247 & 38 & 8 & $\mathrm{Y}$ \\
\hline 2015 & Kupcinskas & Latvia & Caucasian & $\mathrm{HB}$ & Taqman & Colorectal & 191 & 364 & 56 & 84 & 51 & 99 & 180 & 85 & 7 & $\mathrm{Y}$ \\
\hline 2015 & Sun & China & Asian & HB & Taqman & Gastric & 692 & 774 & 319 & 308 & 65 & 403 & 299 & 72 & 9 & $\mathrm{Y}$ \\
\hline 2015 & Zhang & China & Asian & $\mathrm{HB}$ & Sequenom & Gastric & 436 & 451 & 190 & 208 & 38 & 231 & 184 & 36 & 8 & $\mathrm{Y}$ \\
\hline 2014 & Kupcinskas & Lithuania & Caucasian & $\mathrm{HB}$ & Taqman & Gastric & 249 & 232 & 34 & 113 & 102 & 62 & 116 & 54 & 8 & $\mathrm{Y}$ \\
\hline 2014 & Wang & China & Asian & $\mathrm{HB}$ & Taqman & Gastric & 283 & 275 & 131 & 134 & 18 & 149 & 108 & 18 & 9 & $\mathrm{Y}$ \\
\hline 2013 & $\mathrm{Ju}$ & China & Asian & HB & sequencing & Gastric & 155 & 210 & 67 & 65 & 23 & 107 & 87 & 16 & 8 & $\mathrm{Y}$ \\
\hline 2013 & Ono & Japan & Asian & $\mathrm{HB}$ & Taqman & Gallbladder & 44 & 173 & 9 & 23 & 12 & 29 & 76 & 68 & 8 & $\mathrm{Y}$ \\
\hline 2012 & Kim & Korea & Asian & $\mathrm{HB}$ & MassARRAY & Breast & 453 & 460 & 121 & 217 & 115 & 115 & 239 & 106 & 8 & $\mathrm{Y}$ \\
\hline 2011 & Shen & China & Asian & PB & DHPLC & Gastric & 60 & 60 & 24 & 31 & 5 & 29 & 26 & 5 & 9 & $\mathrm{Y}$ \\
\hline 2011 & Joung & Korea & Asian & HB & MassARRAY & Prostate & 194 & 168 & 45 & 100 & 49 & 46 & 85 & 37 & 9 & $\mathrm{Y}$ \\
\hline 2010 & $\mathrm{Ou}$ & China & Asian & $\mathrm{HB}$ & PCR/LDR & Gastric & 196 & 246 & 99 & 85 & 12 & 130 & 102 & 14 & 8 & $\mathrm{Y}$ \\
\hline 2010 & $\mathrm{Lu}$ & China & Asian & PB & PCR-RFLP & Gastric & 1043 & 1082 & 500 & 464 & 79 & 602 & 402 & 78 & 8 & $\mathrm{Y}$ \\
\hline 2009 & $\mathrm{Wu}$ & China & Asian & PB & PCR-RFLP & Gastric & 1724 & 1002 & 789 & 793 & 142 & 492 & 429 & 81 & 9 & $\mathrm{Y}$ \\
\hline 2009 & Matsuo & Japan & Asian & $\mathrm{HB}$ & Taqman & Gastric & 707 & 707 & 331 & 328 & 48 & 274 & 337 & 96 & 8 & $\mathrm{Y}$ \\
\hline 2008 & Sakamoto & Korea & Asian & HB & Taqman & Gastric & 865 & 390 & 134 & 453 & 278 & 122 & 175 & 93 & 7 & $\mathrm{Y}$ \\
\hline 2008 & Sakamoto & Japan & Asian & $\mathrm{HB}$ & GWAS & Gastric & 1525 & 1397 & 97 & 691 & 737 & 211 & 650 & 536 & 9 & $\mathrm{Y}$ \\
\hline
\end{tabular}

SOC: source of control; HB: hospital-based controls; PB: population-based controls;

NOS: Newcastle-Ottawa Scale; HWE: Hardy-Weinberg equilibrium.

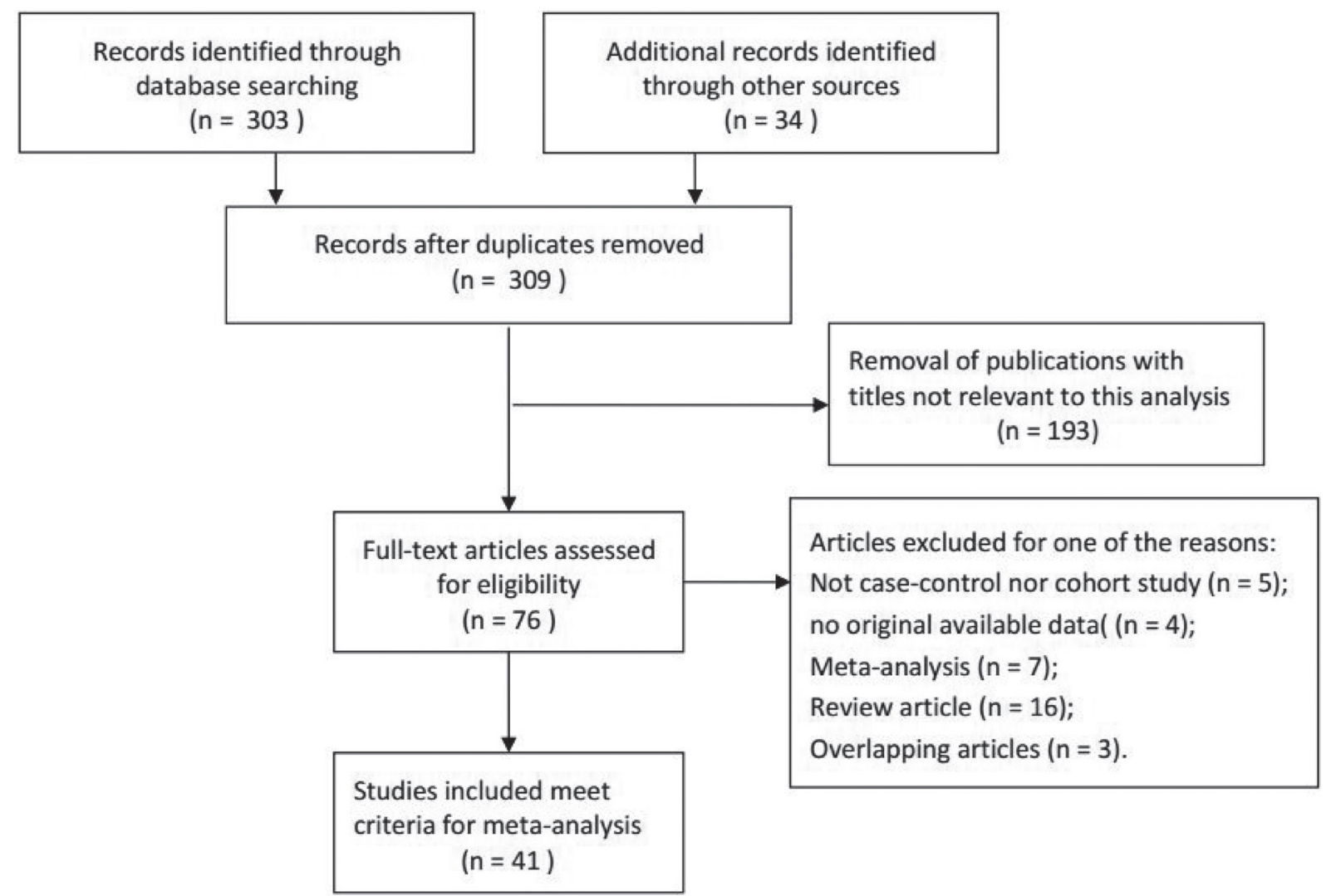

Figure 1: Flowchart of literature search and selection process. 
model: pooled $\mathrm{OR}=1.2995 \% \mathrm{CI}: 1.21-1.38$; heterozygote model: pooled $\mathrm{OR}=1.25$, 95\% CI: 1.18-1.32; allele model: pooled $\mathrm{OR}=1.14,95 \% \mathrm{CI}: 1.07-1.19$ ) (Figure 2). Besides, the stratification analyses by ethnicity found that the results were significant in Asian and Caucasian populations. What's more, in the subgroup analysis by source of controls, carriers of T allele in PSCA rs2294008 were a strong risk factor of cancer in both populationbased controls and hospital-based controls.

In the PSCA rs2976392 polymorphism, we found this polymorphism was significantly associated with risk of cancer (dominant model: pooled $\mathrm{OR}=1.30,95 \% \mathrm{CI}$ : $1.11-1.53$; recessive model: pooled $\mathrm{OR}=1.12,95 \% \mathrm{CI}$ : 0.94-1.33; homozygote model: pooled $\mathrm{OR}=1.3095 \%$ CI: 0.99-1.70; heterozygote model: pooled $\mathrm{OR}=1.28$, 95\% CI: 1.11-1.49; allele model: pooled $\mathrm{OR}=1.17$, 95\% CI: 1.05-1.31). Stratification analyses by type of cancer also detected that rs2976392 polymorphism increased cancer risk only in gastric cancer (dominant model: pooled $\mathrm{OR}=1.43,95 \% \mathrm{CI}: 1.18-1.74$; recessive model: pooled $\mathrm{OR}=1.14,95 \% \mathrm{CI}$ : 0.91-1.43; homozygote model: pooled $\mathrm{OR}=1.4195 \% \mathrm{CI}: 1.23-1.61$; heterozygote model: pooled $\mathrm{OR}=1.41,95 \% \mathrm{CI}: 1.19-1.67$; allele model: pooled $\mathrm{OR}=1.24$, 95\% CI: 1.08-1.41) (Figure 3). Moreover, in the stratification analyses by ethnicity, the significant results were only in Asian populations (dominant model: pooled $\mathrm{OR}=1.29,95 \% \mathrm{CI}: 1.09-1.53$; recessive model: pooled $\mathrm{OR}=1.06,95 \% \mathrm{CI}$ : 0.89-1.27; homozygote model: pooled $\mathrm{OR}=1.24$ 95\% CI: 0.93-1.64; heterozygote model: pooled $\mathrm{OR}=1.29,95 \% \mathrm{CI}: 1.11-1.51$; allele model: pooled $\mathrm{OR}=1.15$, 95\% CI: 1.03-1.29). Lastly, increased cancer susceptibility associated with PSCA rs2976392 was also observed in population-based and hospital-based studies.

\section{Sensitivity analysis}

Sensitivity analysis was carried out to distinguish their influence of each individual study on the combined values by repeating the meta-analysis through sequentially deleting the single studies study each time. The sensitivity analysis of associations for PSCA rs2294008 C>T and rs2976392 $\mathrm{G}>\mathrm{A}$ polymorphisms with the risk of cancer in five types of models (dominant model, recessive model, homozygous model, heterozygous model and allele model) was listed in Supplementary Figure 1, which demonstrated stability and reliability of results for such associations.

\section{Publication bias}

We assessed the potential publication bias for the all available data by the Begg's funnel plot and Egger's test and the results were shown in Figure 4. No symmetric distribution was seemed in the shapes of the funnel plots for the dominant model, indicating no evidence of significant publication bias, which was also confirmed using Egger's test (rs2294008 $\mathrm{C}>\mathrm{T}: P=0.423$; rs $2976392 \mathrm{G}>\mathrm{A}: P=0.842$ ).

\section{Trial sequential analysis results}

Subsequently, the cumulative Z-curve exceeded the monitoring boundaries and the information size in the PSCA rs2294008 polymorphism by TSA, suggesting sufficient evidence of such association. In addition, the results in the PSCA rs2976392 polymorphism were proved to be solid with sufficient evidence, because of exceeding the trial sequential monitoring boundary. As a result, this findings revealed PSCA rs2294008 C>T and rs2976392 $\mathrm{G}>$ A polymorphisms were strongly associated with cancer risk (Figure 5).

\section{DISCUSSION}

The PSCA gene belongs to a member of Ly-6/Thy1 family of glycosylphosphatidyl-inositol (GPI)-anchored cell-surface proteins and plays a critical role in multiple cellular events, including cell adhesion, proliferation, and survival [7]. The over-expression of PSCA was initially reported in prostate cancer [36]. Besides, its highexpression is significantly associated with poor prognosis including seminal vesicle invasion, capsular involvement and Gleason score [49]. Therefore, PSCA has been considered as a biomarker of diagnosis and prognosis, as well as a target of therapy for prostate cancer. Moreover, some solid cancer including ovarian mucinous tumor, pancreatic cancer, renal cell carcinoma and bladder cancer have also existed the expression of PSCA [50]. In contrast with observations in prostate cancer, PSCA expression is down-regulated in several cancers, such as gastric cancer, bladder cancer, and gallbladder carcinoma [13]. Morover, PSCA may have tumor-suppressing function in the gastric epithelium in these specific type of cancers.

Previous studies have investigated the associations of PSCA polymorphisms with various cancer susceptibility [51-53]. For instance, Chandra et al. [52] demonstrated that the PSCA polymorphisms was risk factors for cancer in Asian Population. Besides, Gao et al. [53] found that PSCA rs2294008 polymorphism possessed association with bladder cancer risk. Nevertheless, these results are discrepant and even conflicting. A possible reason arised from the differences in study design, sample size, source of controls, race and genotyping method. All these contributed to the limited statistical power in the published studies. Hence, as we included more studies about the associations between PSCA polymorphisms and the risk of cancer, this meta-analysis was carried out to provide more reliable conclusion to reveal the real associations compared the previous meta-analyses [51]. Furthermore, TSA was used to clarify whether the evidence for the results was sufficient.

As a powerful tool, meta-analysis can provide more sufficient results compared to a single study especially in analyzing unexplained studies [54]. As a result, we suggested there existed a much stronger advantage to 

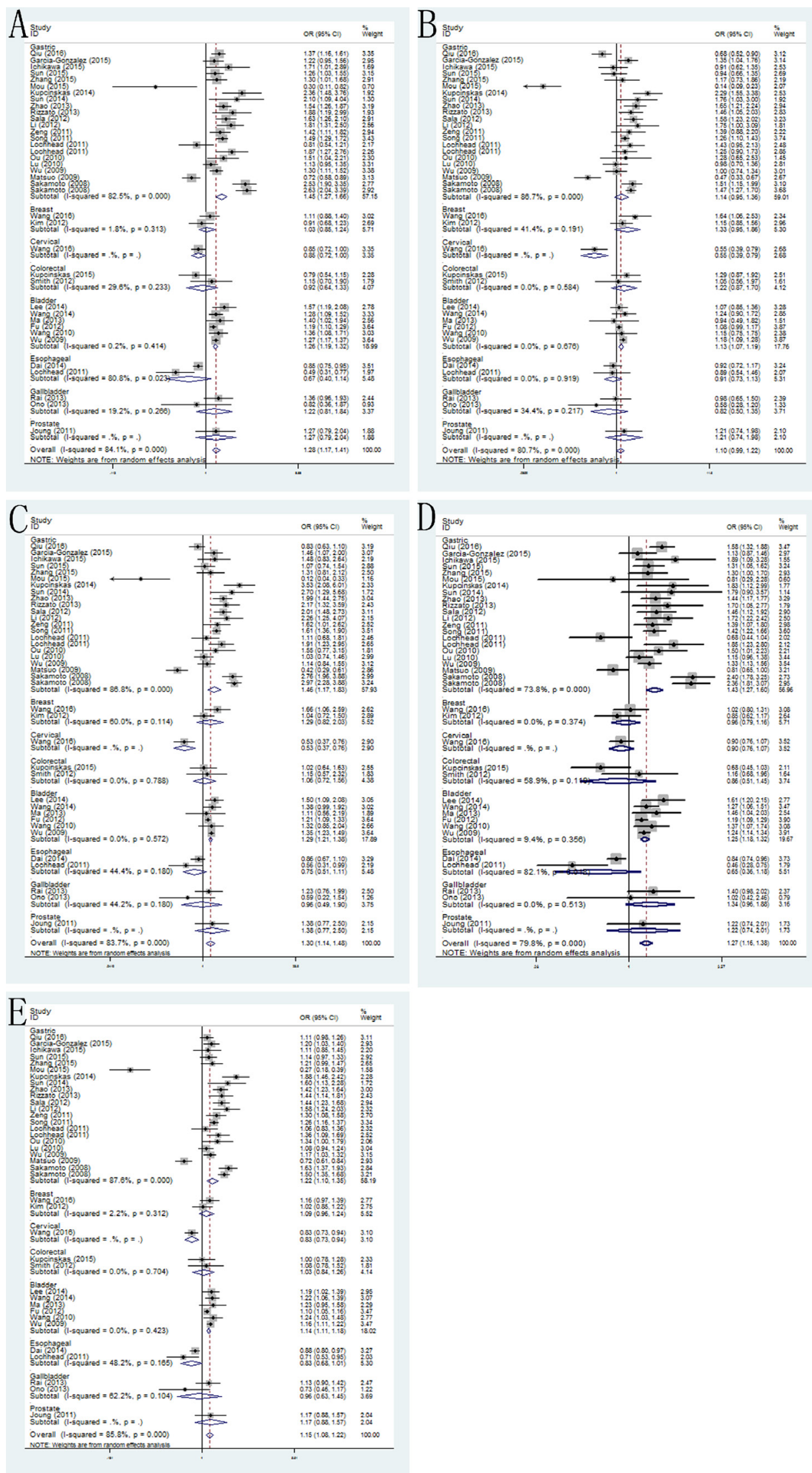

Figure 2: Forest plots of the association between PSCA rs2294008 C $>\mathrm{T}$ polymorphism and cancer susceptibility in the stratification analyses by type of cancer. (A) dominant model; (B) recessive model; (C) homozygous model; (D) heterozygous model; (E) allele model. 

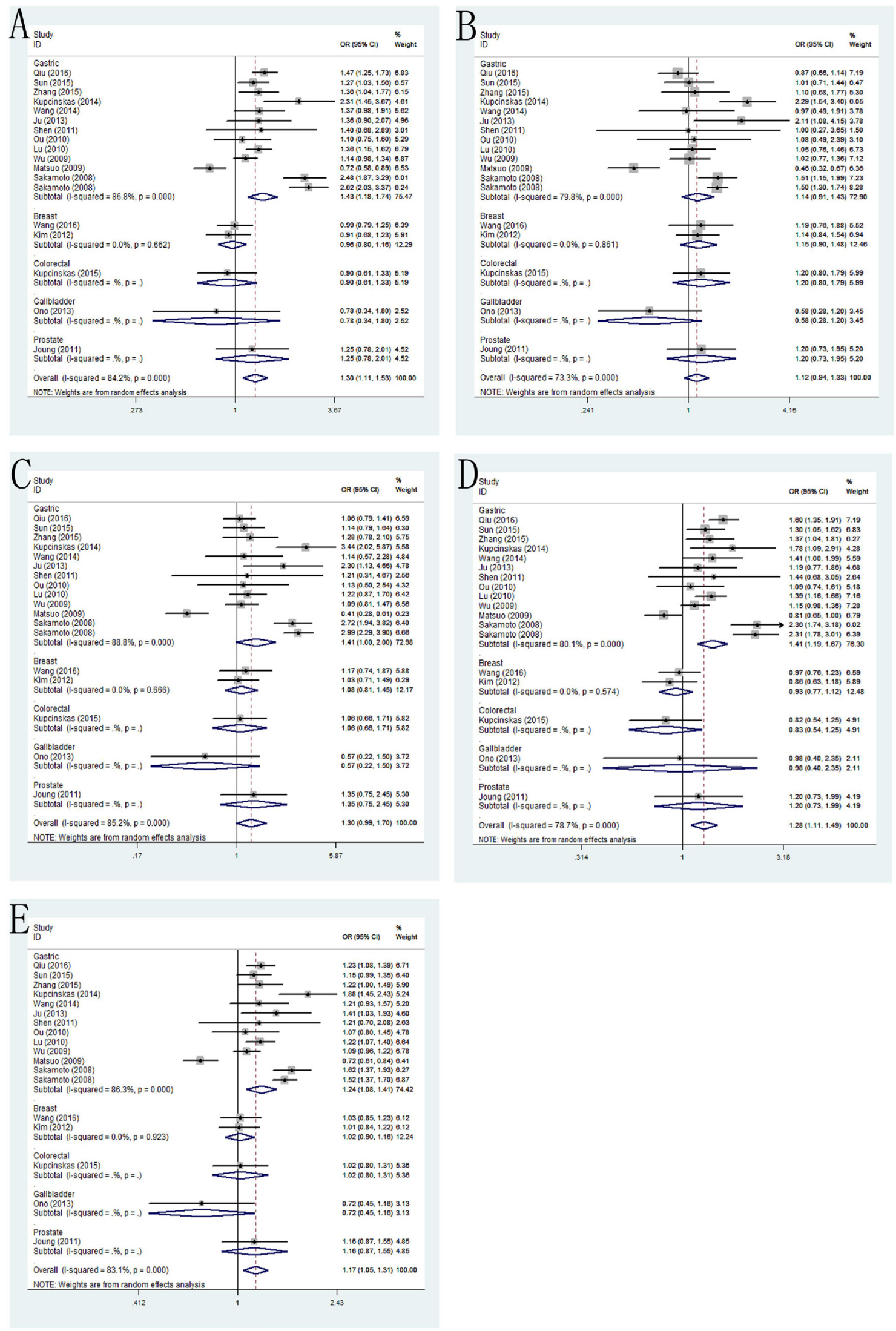

Figure 3: Forest plots of the association between PSCA rs2976392 G>A polymorphism and cancer susceptibility in the stratification analyses by type of cancer. (A) dominant model; (B) recessive model; (C) homozygous model; (D) heterozygous model; (E) allele model. 
prove the association between PSCA rs2294008 C $>$ T and rs2976392 G>A polymorphisms with the susceptibility to cancer. On the one hand, further researches in different stratified analysis were necessary in these meta-analyses. On the other hand, we for the first time applied TSA to reduce the risk of type I error and testify whether the evidence of our results was reliable. The results suggested that significantly elevated cancer risk was associated with the PSCA rs2294008 C>T polymorphism levels, particularly in patients with gastric cancer and bladder cancer. Meanwhile, PSCA rs2976392 G>A polymorphism significantly increased cancer risk only in gastric cancer.

After stratified analysis by type of cancer, the results showed PSCA rs2294008 C $>$ T and rs2976392 $\mathrm{G}>\mathrm{A}$ polymorphisms statistically increased cancer risk, especially in gastric cancer and bladder cancer instead of breast cancer, cervical cancer, colorectal cancer and other cancers. Different kinds of cancer have specific characteristic of diverse aspects, which might lead to different statistical results. In addition, the different type
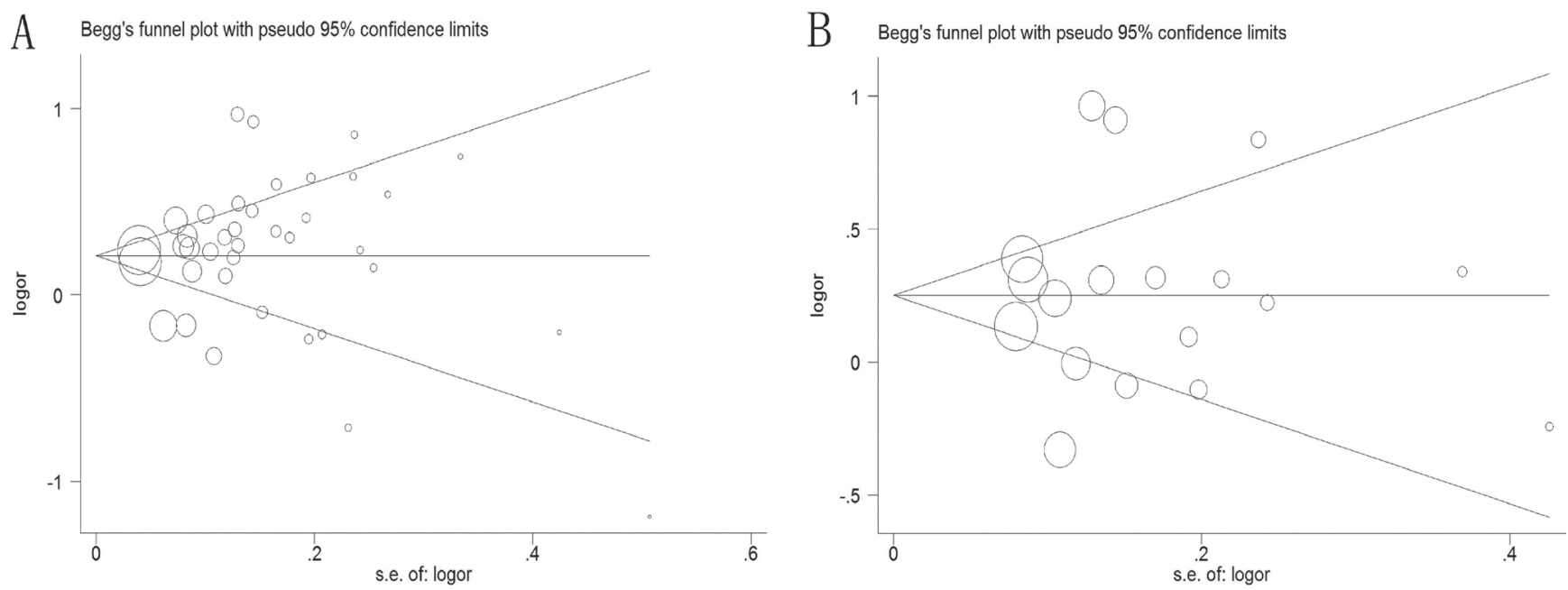

Figure 4: Begg's funnel plot of publication bias test in dominant model. (A) PSCA rs2294008 C>T polymorphism; (B) PSCA rs2976392 G>A polymorphism.

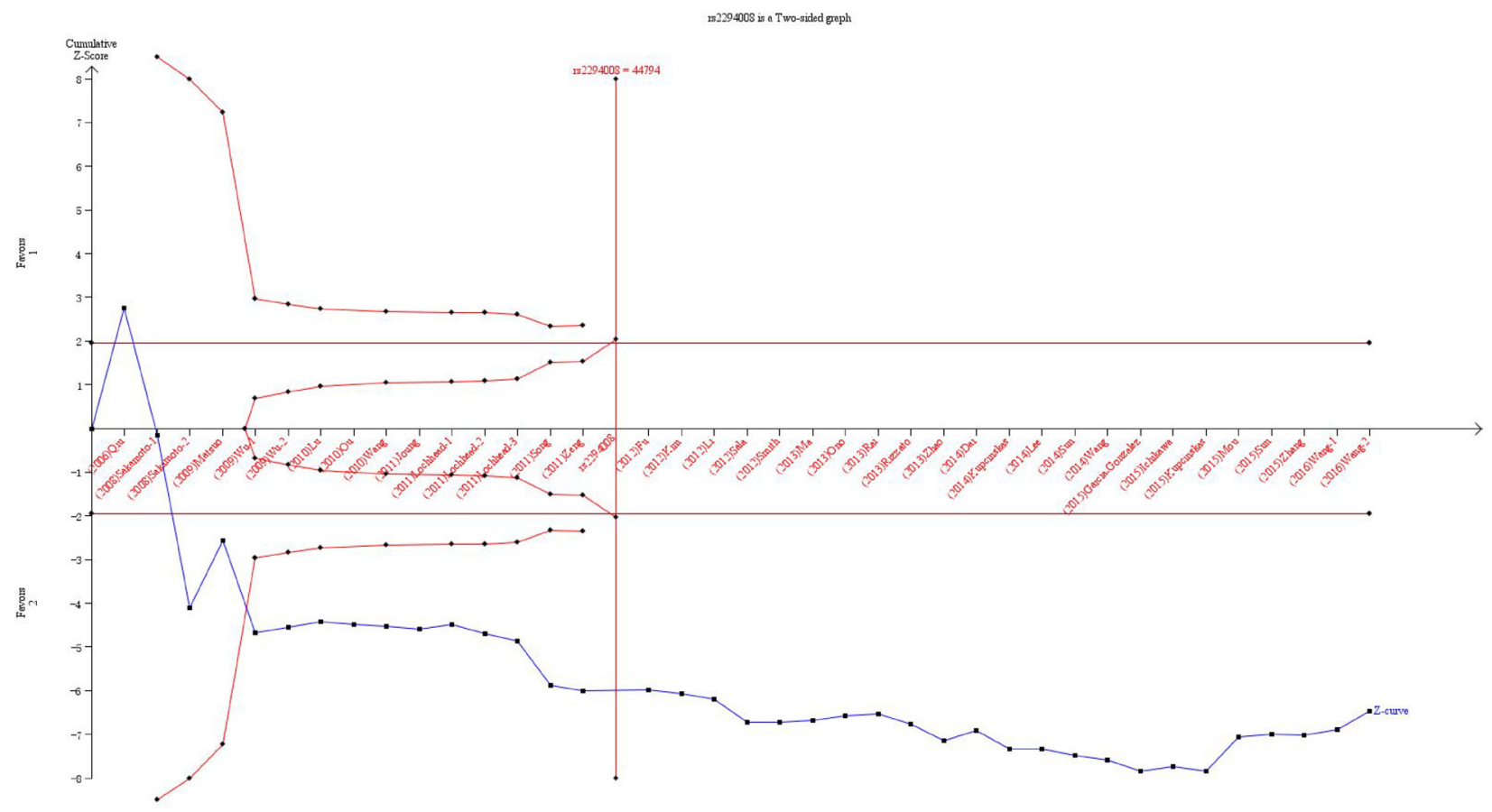

Figure 5: Trial sequential analysis of the association between PSCA polymorphisms and the risk of cancer. The required information size was calculated based on a two side $\alpha=5 \%, \beta=20 \%$, and a $95 \%$ confidence intervals. (A) PSCA rs $2294008 \mathrm{C}>\mathrm{T}$ polymorphism; (B) PSCA rs2976392 G>A polymorphism. 
of cancer has distinctive polymorphism sites. Therefore, only specific polymorphism site might be associated with a certain type of tumor.

These findings of subgroup analyses based on ethnicity and source of control can be explained as follows. In the subgroup analysis by ethnicity, significantly increased cancer risk was shown in Asian and Caucasian populations in PSCA rs2294008 C > T polymorphism. Besides, PSCA rs2976392 G>A polymorphism increased risk of cancer only in Asian populations. Though the exact mechanism was unclear, it was possible that different ethnic groups with various genetic backgrounds might have different SNPs in the developing of cancer. Meanwhile, it is important to meet the unified enrollment criteria and select larger sample size studies, which could make the results more reliable. In addition, we conducted stratified analysis by source of controls and the result was detected significantly both in population-based and hospital-based populations. In this meta-analysis, the results were in concordance with these hypotheses of previous studies, which needed to further prove that PSCA rs2294008 and rs2976392 played an important role in cancer susceptibility as far as possible in all relevant articles published in the future.

As an useful approach, TSA is introduced to calculate the required information size for this metaanalysis with the adaptation of monitoring boundaries, in order to reduce the risk of type I error [55-57]. Besides, we took advantage of TSA with all included trials to estimate whether a sufficient level of evidence had been reached and whether further trials were necessary [58-60]. When a $P$ value is sufficiently small to show the anticipated effect, it is believed that the application of TSA shows the potential to be more reliable compared to the traditional meta-analysis. For findings of risk of cancer in PSCA rs2294008 C>T polymorphism, the cumulative Z-curve crossed not only the monitoring boundaries but also the sufficient information size, suggesting that additional new clinical trial should not be needed. Moreover, for results of risk of cancer in PSCA rs2976392 G>A polymorphism, the cumulative $\mathrm{Z}$-curve not exceeding the required sample size crossed the trial sequential monitoring boundaries, which indicated that our conclusion had reached a sufficient level of evidence $[61,62]$. In consequence, it was strongly of the view that our results in the current meta-analysis were based on firm evidence of effect, and no further studies was needed to investigate such associations.

Although the overall robust statistical evidence including the implementation of TSA was to estimate a slight association by this meta-analysis, some limitations of this meta-analysis should be taken into consideration when interpreting the present results. Firstly, some published studies involved in the PSCA polymorphisms are not accord with the HWE, resulting in potential bias during control selection or genotyping errors. Secondly, because of existing significant heterogeneity in this meta- analysis, it was very likely the results were interpreted. Thirdly, the effect of multiple confounders such as age, gender, life-style may also play an important role in the development of cancer, but we could not make these subgroup analysis due to insufficient data on the basis of these factors. What's more, as a multi-factorial disease, the pathogenesis of cancer is closely related complex interactions between a variety of genetic factors and environmental backgrounds, suggesting risk of cancer would not be influenced by any single gene. Therefore, more new-designed studies about exploring the risk effects of these two SNPs in susceptibility to cancer needed to be further validated in subsequent studies. Accordingly, it is required that more studies be conducted to provide a more definitive conclusion.

\section{MATERIALS AND METHODS}

A comprehensive literature search was systematically conducted using the electronic databases PubMed, EMBASE and Web of Science for potential relevant studies, which investigated the association between PSCA rs2294008 C>T and rs2976392 G>A polymorphisms and risk of cancer, covering all the papers published until September 1st, 2016. The combinations of the following keywords were used: "prostate stem cell antigen", "PSCA polymorphisms", "rs2294008" or "rs2976392", and "gene", "variant", "polymorphism" or "mutation", and "caner", "carcinoma" or "neoplasms". Eligible literatures were retrieved from all publications. Besides, additional literature was further collected manually from reference lists of reviews to make sure all potential eligible publications. Moreover, if studies had partly familiar or overlapping subjects, only the latest or largest sample size was adopted in this meta-analysis.

\section{Inclusion and exclusion criteria}

Studies were included if they met the inclusion criteria as follows: (1) a case-control or cohort design; (2) investigate or report the relationship between PSCA polymorphisms and cancer susceptibility; (3) sufficient genotype frequency data provided to calculate the odds ratio (OR) and $95 \%$ confidence interval (CI). In addition, the major excluding criterion was as follows: (1) no relevant genotype frequency data or overlapping data; (2) reviews or conference abstracts; (3) no case-control studies; (4) providing duplicates of previous publication with others.

\section{Data extraction}

According to the eligibility criteria, data were extracted from each manuscript independently by two investigators (Qin ZQ and Tang JY). Besides, any disagreement would be solved by a discussion with a 
third investigator ( $\mathrm{Li} \mathrm{X}$ ) to reach a consensus on all the extracted information. From each article, first author's name, year of publication, country, ethnicity, source of controls (population-based or hospital-based), genotyping method, type of cancer, sample size of cases and controls, frequency of PSCA rs2294008 and rs2976392 gene polymorphisms in cases and controls respectively, and the results of the HWE test were recorded in a standardized form.

\section{Quality assessment}

The quality of the studies was assessed using the validated Newcastle-Ottawa Scale (NOS) for nonrandomized studies, including case-control and cohort studies. Separate NOS scales were developed for cohort and case-control studies. It has not been published in peerreviewed journals so far, although NOS has been widely utilized. NOS awards eight points to each case-control study (four for quality of selection, one for comparability, and three for quality of exposure). A study can be awarded a maximum of one star for each point within the selection and exposure categories, and a maximum of two stars can be given for comparability. Besides, NOS also awards eight points to each cohort study (four for quality of selection, one for comparability, and three for quality of outcome). A study can be awarded a maximum of one star for each point within the selection and outcome categories, and a maximum of two stars can be given for comparability. We considered studies with scores of more than 7 as high-quality studies, and those with scores of 7 or less as low-quality studies.

\section{Statistical analysis}

The crude odds ratios (ORs) with 95\% confidence intervals (CIs) were measured to evaluate the strength of association between the PSCA rs2294008 and rs2976392 gene polymorphisms with overall cancer susceptibility under these five genetic comparison models: dominant model, recessive model, homozygous model, heterozygous model and allele model, based on the genotype frequency distribution in cases and controls. An OR value $>1$ indicated a significantly increased cancer risk, while an OR value $<1$ stood for more benefit in risk of cancer. The goodness-of-fit chi-square test was adopted to check HWE among controls, and the deviation was regarded significant disequilibrium at the 0.05 level. The between-study heterogeneity was estimated using the chi-square-based $\mathrm{Q}$ test and quantified with the $\mathrm{I}^{2}$ statistic. When $P<0.05$ was considered the presence of significant heterogeneity among studies, the random-effects model (DerSimonianLaird method) would be conducted. In addition, the pooled OR was calculated using the fixed-effects model (MantelHaenszel method) in the absence of heterogeneity. After that, subgroup analysis was further performed by type of cancer, ethnicity and source of controls. In sensitivity analysis, each study was omitted each time and the pooled ORs with $95 \%$ CIs were recalculated to measure the stability of pooled results. Publication bias between the studies was performed using Begg's funnel plots and Egger's linear regression test and by visual inspection of the funnel plot. All $P$ values were two-sided and a $P<0.05$ was considered statistically significant. All statistical data was carried out by Stata software (version 12.0; StataCorp LP, College Station, TX).

\section{Trial sequential analysis}

Outcome of meta-analysis might be prone to systematic or random errors owing to repeated significance testing of accumulated data and collecting sparse data, when cumulative meta-analyses were updated with addition of new publishing studies $[56,60,63]$. Thus, TSA was performed to reduce the risk of type I errors and confirmed more statistical reliability of the data by estimation of required information size with an adjusted threshold for statistical significance $[57,58]$. In the current meta-analysis, TSA was performed with a desire to maintain a $95 \%$ confidence intervals, a $20 \%$ relative risk reduction, an overall $5 \%$ risk a type I error and a statistical test power of $80 \%$ (20\% risk of the type II error), which meant that the required information size was calculated and the trial sequential monitoring boundaries was constructed. When the cumulative Z-curve (the blue line) crossed the trial sequential monitoring boundary (sloping red line) or exceeded the required information size (vertical red line), a sufficient level of evidence might have been reached and no further studies were needed. Otherwise, if the blue line did not cross any of the boundaries and the vertical red line has not been reached, additional clinical trials are needed to obtain sufficient evidence by reaching the adequate required information size [59-60, 64]. The trial sequential analysis software (TSA, version 0.9; Copenhagen Trial Unit, Copenhagen, Denmark, 2011) was carried out in this study.

\section{CONCLUSIONS}

This current meta-analysis provided statistical evidence supporting that the PSCA rs2294008 C $>$ T and rs2976392 $\mathrm{G}>\mathrm{A}$ polymorphisms increased the risk of cancer, especially in gastric cancer and bladder cancer. Therefore, the PSCA s2294008 C > T and rs2976392 $\mathrm{G}>\mathrm{A}$ polymorphisms might be considered an ideal marker in the prediction of cancer in the subsequent studies. Nevertheless, more well-designed studies need to be further checked with a sufficiently large number of participants to substantiate these real associations. 


\section{Ethical statements}

None declared.

\section{ACKNOWLEDGMENTS AND FUNDING}

This work is supported by the grant from National Natural Science Foundation of China (81370781, 81670608, 81600514).

\section{CONFLICTS OF INTEREST}

We declare that we have no conflicts of interest.

\section{REFERENCES}

1. Siegel RL, Miller KD, Jemal A. Cancer Statistics, 2017. CA Cancer J Clin. 2017; 67:7-30.

2. Sharma KL, Rai R, Srivastava A, Sharma A, Misra S, Kumar A, Mittal B. A multigenic approach to evaluate genetic variants of PLCE1, LXRs, MMPs, TIMP, and CYP genes in gallbladder cancer predisposition. Tumour Biol. 2014; 35:8597-8606.

3. Ullah MF, Aatif M. The footprints of cancer development: Cancer biomarkers. Cancer Treat Rev. 2009; 35:193-200.

4. Yuasa Y. Epigenetics in molecular epidemiology of cancer a new scope. Adv Genet. 2010; 71:211-235.

5. Castro-Giner F, Ratcliffe P, Tomlinson I. The mini-driver model of polygenic cancer evolution. Nat Rev Cancer. $2015 ; 15: 680-685$.

6. Carlson CS, Eberle MA, Kruglyak L, Nickerson DA. Mapping complex disease loci in whole-genome association studies. Nature. 2004; 429:446-452.

7. Raff AB, Gray A, Kast WM. Prostate stem cell antigen: a prospective therapeutic and diagnostic target. Cancer Lett. 2009; 277:126-132.

8. Ono H, Hiraoka N, Lee YS, Woo SM, Lee WJ, Choi IJ, Saito A, Yanagihara K, Kanai Y, Ohnami S, Chiwaki F, Sasaki H, Sakamoto H, et al. Prostate stem cell antigen, a presumable organ-dependent tumor suppressor gene, is down-regulated in gallbladder carcinogenesis. Genes Chromosomes Cancer. 2012; 51:30-41.

9. Wente MN, Jain A, Kono E, Berberat PO, Giese T, Reber HA, Friess H, Buchler MW, Reiter RE, Hines OJ. Prostate stem cell antigen is a putative target for immunotherapy in pancreatic cancer. Pancreas. 2005; 31:119-125.

10. Amara N, Palapattu GS, Schrage M, Gu Z, Thomas GV, Dorey F, Said J, Reiter RE. Prostate stem cell antigen is overexpressed in human transitional cell carcinoma. Cancer Res. 2001; 61:4660-4665.

11. Fu YP, Kohaar I, Rothman N, Earl J, Figueroa JD, Ye Y, Malats N, Tang W, Liu L, Garcia-Closas M, Muchmore B, Chatterjee N, Tarway $\mathrm{M}$, et al. Common genetic variants in the PSCA gene influence gene expression and bladder cancer risk. Proc Natl Acad Sci USA. 2012; 109:4974-4979.

12. Sakamoto H, Yoshimura K, Saeki N, Katai H, Shimoda T, Matsuno Y, Saito D, Sugimura H, Tanioka F, Kato S, Matsukura N, Matsuda N, Nakamura T, et al. Gnetic variation in PSCA is associated with susceptibility to diffuse-type gastric cancer. Nat Genet. 2008; 40:730-740.

13. Qiu LX, Cheng L, He J, Zhou ZR, Wang MY, Zhou F, Guo WJ, Li J, Sun MH, Zhou XY, Wang YN, Yang YJ, Wang JC, et al. PSCA polymorphisms and gastric cancer susceptibility in an eastern Chinese population. Oncotarget. 2016; 7:9420-9428. doi: 10.18632/oncotarget.7137.

14. Wang M, Wang X, Fu SW, Liu X, Jin T, Kang H, Ma X, Lin S, Guan H, Zhang S, Liu K, Dai C, Zhu Y, et al. Singlenucleotide polymorphisms in PSCA and the risk of breast cancer in a Chinese population. Oncotarget. 2016; 7:2766527675. doi: 10.18632/oncotarget.8491.

15. Wang S, Wu S, Zhu H, Ding B, Cai Y, Ni J, Wu Q, Meng Q, Zhang X, Zhang C, Li X, Wang M, Chen R, et al. PSCA rs2294008 polymorphism contributes to the decreased risk for cervical cancer in a Chinese population. Sci Rep. 2016; $6: 23465$

16. Garcia-Gonzalez MA, Bujanda L, Quintero E, Santolaria S, Benito R, Strunk M, Sopena F, Thomson C, PerezAisa A, Nicolas-Perez D, Hijona E, Carrera-Lasfuentes P, Piazuelo E, et al. Association of PSCA rs2294008 gene variants with poor prognosis and increased susceptibility to gastric cancer and decreased risk of duodenal ulcer disease. Int J Cancer. 2015; 137:1362-1373.

17. Ichikawa H, Sugimoto M, Uotani T, Sahara S, Yamade M, Iwaizumi M, Yamada T, Osawa S, Sugimoto $K$, Miyajima H, Yamaoka Y, Furuta T. Influence of prostate stem cell antigen gene polymorphisms on susceptibility to Helicobacter pylori-associated diseases: a case-control study. Helicobacter. 2015; 20:106-113.

18. Kupcinskas J, Gyvyte U, Bruzaite I, Leja M, KupcinskaiteNoreikiene R, Pauzas H, Tamelis A, Jonaitis L, Skieceviciene J, Kiudelis G. Common Genetic Variants of PSCA, MUC1 and PLCE1 Genes are not Associated with Colorectal Cancer. Asian Pac J Cancer Prev. 2015; 16:6027-6032.

19. Mou X, Li T, Wang J, Ali Z, Zhang Y, Chen Z, Deng Y, Li S, Su E, Jia Q, He N, Ni J, Cui D. Genetic Variation of BCL2 (rs2279115), NEIL2 (rs804270), LTA (rs909253), PSCA (rs2294008) and PLCE1 (rs3765524, rs10509670) Genes and Their Correlation to Gastric Cancer Risk Based on Universal Tagged Arrays and Fe3O4 Magnetic Nanoparticles. J Biomed Nanotechnol. 2015; 11:2057-2066.

20. Sun H, Wu X, Wu F, Li Y, Yu Z, Chen X, Chen Y, Yang W. Associations of genetic variants in the PSCA, MUC1 and PLCE1 genes with stomach cancer susceptibility in a Chinese population. Plos One. 2015; 10:e117576.

21. Zhang W, Liang P, Wang W, Dai P, Wang Q, Yan W, Zhao J, Sun J, Peng Y, Cui D, Yan Z. The Influence of PSCA Gene 
Variation on Its Expression and Gastric Adenocarcinoma Susceptibility in the Northwest Chinese Population. Int J Mol Sci. 2015; 16:11648-11658.

22. Dai N, Zheng M, Wang C, Ji Y, Du J, Zhu C, He Y, Zhu M, Zhu X, Sun M, Dai J, Ma H, Chen J, et al. Genetic variants at $8 \mathrm{q} 24$ are associated with risk of esophageal squamous cell carcinoma in a Chinese population. Cancer Sci. 2014; 105:731-735.

23. Kupcinskas J, Wex T, Link A, Bartuseviciute R, Dedelaite M, Kevalaite G, Leja M, Skieceviciene J, Kiudelis G, Jonaitis L, Kupcinskas L, Malfertheiner P. PSCA and MUC1 gene polymorphisms are associated with gastric cancer and pre-malignant gastric conditions [corrected]. Anticancer Res. 2014; 34:7167-7175.

24. Lee JH, Song HR, Kim HN, Kweon SS, Yun YW, Choi JS, Jung SI, Kwon DD, Kim SH, Choi YD, Shin MH. Genetic variation in PSCA is associated with bladder cancer susceptibility in a Korean population. Asian Pac J Cancer Prev. 2014; 15:8901-8904.

25. Sun Y, Gu J, Ajani JA, Chang DW, Wu X, Stroehlein JR. Genetic and intermediate phenotypic susceptibility markers of gastric cancer in Hispanic Americans: a case-control study. Cancer-Am Cancer Soc. 2014; 120:3040-3048.

26. Wang P, Ye D, Guo J, Liu F, Jiang H, Gong J, Gu C, Shao Q, Sun J, Zheng SL, Yu H, Lin X, Xia G, et al. Genetic score of multiple risk-associated single nucleotide polymorphisms is a marker for genetic susceptibility to bladder cancer. Genes Chromosomes Cancer. 2014; 53:98-105.

27. Ma Z, Hu Q, Chen Z, Tao S, Macnamara L, Kim ST, Tian L, Xu K, Ding Q, Zheng SL, Sun J, Xia G, Xu J. Systematic evaluation of bladder cancer risk-associated singlenucleotide polymorphisms in a Chinese population. Mol Carcinog. 2013; 52:916-921.

28. Ono H, Chihara D, Chiwaki F, Yanagihara K, Sasaki H, Sakamoto H, Tanaka H, Yoshida T, Saeki N, Matsuo K. Missense allele of a single nucleotide polymorphism rs2294008 attenuated antitumor effects of prostate stem cell antigen in gallbladder cancer cells. J Carcinog. 2013; 12:4.

29. Rai R, Sharma KL, Misra S, Kumar A, Mittal B. PSCA gene variants (rs2294008 and rs2978974) confer increased susceptibility of gallbladder carcinoma in females. GENE. 2013; 530:172-177.

30. Rizzato C, Kato I, Plummer M, Munoz N, Canzian F. Genetic variation in PSCA and risk of gastric advanced preneoplastic lesions and cancer in relation to Helicobacter pylori infection. PLOS ONE. 2013; 8:e73100.

31. Zhao J, Geng P, Li Z, Cui S, Zhao J, Wang L, Li J, Ji F, Li G, Shen G, Lin M, Shen C. Prostate stem cell antigen rs2294008 polymorphism differentially contributes to Helicobacter pylori-negative gastric cancer among various populations in China. Mol Clin Oncol. 2013; 1:493-498.

32. Kim SY, Yoo JY, Shin A, Kim Y, Lee ES, Lee YS. Prostate stem cell antigen single nucleotide polymorphisms influence risk of estrogen receptor negative breast cancer in Korean females. Asian Pac J Cancer Prev. 2012; 13:41-48.
33. Li F, Zhong MZ, Li JH, Liu W, Li B. Case-control study of single nucleotide polymorphisms of PSCA and MUC1 genes with gastric cancer in a Chinese. Asian Pac J Cancer Prev. 2012; 13:2593-2596.

34. Sala N, Munoz X, Travier N, Agudo A, Duell EJ, Moreno V, Overvad K, Tjonneland A, Boutron-Ruault MC, ClavelChapelon F, Canzian F, Kaaks R, Boeing H, et al. Prostate stem-cell antigen gene is associated with diffuse and intestinal gastric cancer in Caucasians: results from the EPIC-EURGAST study. Int J Cancer. 2012; 130:24172427.

35. Smith C, Lochhead P, Basavaraju U, Hold GL, Fyfe N, Murray GI, El-Omar EM. Lack of association between the rs2294008 polymorphism in the prostate stem cell antigen gene and colorectal neoplasia: a case-control and immunohistochemical study. BMC Res Notes. 2012; 5:371.

36. Joung JY, Lee YS, Park S, Yoon H, Lee SJ, Park WS, Seo HK, Chung J, Kim SY, Hong SH, Kim JS, Lee KH. Haplotype analysis of prostate stem cell antigen and association with prostate cancer risk. J Urol. 2011; 185:2112-2118.

37. Lochhead P, Frank B, Hold GL, Rabkin CS, Ng MT, Vaughan TL, Risch HA, Gammon MD, Lissowska J, Weck MN, Raum E, Muller H, Illig T, et al. Genetic variation in the prostate stem cell antigen gene and upper gastrointestinal cancer in white individuals. Gastroenterology. 2011; 140:435-441.

38. Song HR, Kim HN, Piao JM, Kweon SS, Choi JS, Bae WK, Chung IJ, Park YK, Kim SH, Choi YD, Shin MH. Association of a common genetic variant in prostate stemcell antigen with gastric cancer susceptibility in a Korean population. Mol Carcinog. 2011; 50:871-875.

39. Zeng Z, Wu X, Chen F, Yu J, Xue L, Hao Y, Wang Y, Chen M, Sung JJ, Hu P. Polymorphisms in prostate stem cell antigen gene rs2294008 increase gastric cancer risk in Chinese. Mol Carcinog. 2011; 50:353-358.

40. Lu Y, Chen J, Ding Y, Jin G, Wu J, Huang H, Deng B, Hua Z, Zhou Y, Shu Y, Liu P, Hu Z, Shen J, et al. Genetic variation of PSCA gene is associated with the risk of both diffuse- and intestinal-type gastric cancer in a Chinese population. Int J Cancer. 2010; 127:2183-2189.

41. Ou J, Li K, Ren H, Bai H, Zeng D, Zhang C. Association and haplotype analysis of prostate stem cell antigen with gastric cancer in Tibetans. Dna Cell Biol. 2010; 29:319-323.

42. Wang S, Tang J, Wang M, Yuan L, Zhang Z. Genetic variation in PSCA and bladder cancer susceptibility in a Chinese population. Carcinogenesis. 2010; 31:621-624.

43. Matsuo K, Tajima K, Suzuki T, Kawase T, Watanabe M, Shitara K, Misawa K, Ito S, Sawaki A, Muro K, Nakamura T, Yamao K, Yamamura Y, et al. Association of prostate stem cell antigen gene polymorphisms with the risk of stomach cancer in Japanese. Int J Cancer. 2009; 125:1961-1964.

44. Wu C, Wang G, Yang M, Huang L, Yu D, Tan W, Lin D. Two genetic variants in prostate stem cell antigen and 
gastric cancer susceptibility in a Chinese population. Mol Carcinog. 2009; 48:1131-1138.

45. Wu X, Ye Y, Kiemeney LA, Sulem P, Rafnar T, Matullo G, Seminara D, Yoshida T, Saeki N, Andrew AS, Dinney CP, Czerniak B, Zhang ZF, et al. Genetic variation in the prostate stem cell antigen gene PSCA confers susceptibility to urinary bladder cancer. Nat Genet. 2009; 41:991-995.

46. Wang B, Pang C, Yang G, Ren J, Wang H, Wang Y. An Association Study of SNP rs2976392 in PSCA Gene and Gastric Cancer. Journal of Baotou Medical College. 2014; $1-2$.

47. Ju Y, Diao Y, Song M, Jiang X. PSCA polymorphism rs2976392 in gastric cancer. Chinese Journal of Oncology Prevention and Treatment. 2013; 300-303.

48. Shen G, Zhang C, Zhao J, Geng P, Dou L, Zhang S, Ma D, Li G. A study of relationship between PSCA gene polymorphisms and susceptibility to Tibetan gastric cancer in Qinghai area. Journal of Qinghai Medical College. 2011; 32:169-171.

49. Han KR, Seligson DB, Liu X, Horvath S, Shintaku PI, Thomas GV, Said JW, Reiter RE. Prostate stem cell antigen expression is associated with gleason score, seminal vesicle invasion and capsular invasion in prostate cancer. J Urol. 2004; 171:1117-1121.

50. Saeki N, Gu J, Yoshida T, Wu X. Prostate stem cell antigen: a Jekyll and Hyde molecule? Clin Cancer Res. 2010; 16:3533-3538.

51. Wang M, Wang XJ, Ma YF, Ma XB, Dai ZM, Lv Y, Lin S, Liu XH, Yang PT, Dai ZJ. PSCA rs2294008 C > T polymorphism contributes to gastric and bladder cancer risk. Ther Clin Risk Manag. 2015; 11:237-45.

52. Chandra V, Kim JJ, Gupta U, Mittal B, Rai R. Impact of DCC (rs714) and PSCA (rs2294008 and rs2976392) Gene Polymorphism in Modulating Cancer Risk in Asian Population. Genes (Basel). 2016; 7:7.

53. Gao J, Yang PT, Diao Y, Kang HF, Zhao Y, Lin S, Wang ZM, Wang M, Wang XJ, Dai ZJ. Effects of PSCA rs2294008 $(\mathrm{C} / \mathrm{T})$ and c-MYC rs9642880 (G/T) polymorphisms on bladder cancer: evidence from a meta-analysis. Int J Clin Exp Med. 2015; 8:2156-2164.

54. Munafo MR, Clark TG, Flint J. Assessing publication bias in genetic association studies: evidence from a recent metaanalysis. Psychiatry Res. 2004; 129:39-44.
55. Imberger G, Wetterslev J, Gluud C. Trial sequential analysis has the potential to improve the reliability of conclusions in meta-analysis. Contemp Clin Trials. 2013; 36:254-255.

56. Wetterslev J, Thorlund K, Brok J, Gluud C. Trial sequential analysis may establish when firm evidence is reached in cumulative meta-analysis. J Clin Epidemiol. 2008; 61:64-75.

57. Brok J, Thorlund K, Gluud C, Wetterslev J. Trial sequential analysis reveals insufficient information size and potentially false positive results in many meta-analyses. J Clin Epidemiol. 2008; 61:763-769.

58. Devereaux PJ, Beattie WS, Choi PT, Badner NH, Guyatt GH, Villar JC, Cina CS, Leslie K, Jacka MJ, Montori VM, Bhandari M, Avezum A, Cavalcanti AB, et al. How strong is the evidence for the use of perioperative beta blockers in non-cardiac surgery? Systematic review and meta-analysis of randomised controlled trials. BMJ. 2005; 331:313-321.

59. Pogue J, Yusuf S. Overcoming the limitations of current meta-analysis of randomised controlled trials. Lancet. 1998; 351:47-52.

60. Pogue JM, Yusuf S. Cumulating evidence from randomized trials: utilizing sequential monitoring boundaries for cumulative meta-analysis. Control Clin Trials. 1997; 18:580-593, 661-666.

61. Gluud LL. Bias in clinical intervention research. Am J Epidemiol. 2006; 163:493-501.

62. Altman D, Bland JM. Confidence intervals illuminate absence of evidence. BMJ. 2004; 328:1016-1017.

63. Brok J, Thorlund K, Wetterslev J, Gluud C. Apparently conclusive meta-analyses may be inconclusive--Trial sequential analysis adjustment of random error risk due to repetitive testing of accumulating data in apparently conclusive neonatal meta-analyses. Int J Epidemiol. 2009; 38:287-298.

64. Wetterslev J, Thorlund K, Brok J, Gluud C. Estimating required information size by quantifying diversity in random-effects model meta-analyses. BMC Med Res Methodol. 2009; 9:86. 